\title{
EL CASTILLO ESPAÑOL *
}

\author{
por Leonardo Villena, \\ del Consejo Superior de Investigaciones \\ Científicas
}

\section{Rasgos geográficos e históricos de Iberia}

ANTES de considerar la evolución y características del castillo español, conviene recordar las circunstancias geográficas e históricas que influyeron en la civilización hispana y, por tanto, en sus castillos. La topografía ibérica, una de las más complicadas de Europa, dio forma a la personalidad hispana desde las culturas pre y protohistóricas, que cuentan entre las más antiguas e interesantes de Europa.

Durante la época neolítica una serie de tribus que llamamos iberos se introducen por el Sur, estableciéndose a lo largo del Mediterráneo, llegando al centro de la Península y desarrollando una civilización floreciente, ejemplo de la cual son la Dama de Elche y la Bicha de Balazote. Especial interés tiene la civilización tartésida, que influida, según el profesor Almagro, por los egipcios, alcanza un nivel cultural superior. Tartesos, la actual Andalucía, domina el Mediterráneo occidental, donde impone su cultura y su cerámica campaniforme, que llega hasta Centroeuropa.

Más tarde, en la edad de bronce, tribus celtas atraviesan los Pirineos desarrollando, especialmente en el noroeste, la cultura de los castros. Los celtas se mezclan con los iberos en Castilla, la altiplanicie central defendida de las influencias climáticas y humanas procedentes del mar por una serie de cadenas de montañas que le dan un clima seco, unos grandes contrastes y una clara personalidad.

La Iberia asi poblada fue el finis terrae del mundo antiguo, la puerta oeste del Mediterráneo (alrededor del cual se inició y desarrolló la civilización occidental), un lugar celebrado y codiciado por los pueblos civilizadores orientales, que se disputaron el dominio de este punto crucial y la explotación de sus minas y puertos. También fue objeto de su curiosidad intelectual, como lo demuestran las referencias bíblicas y homéricas. Todo ello hizo que nuestro país tuviese un desarrollo cultural muy anterior y avanzado al de Europa central o nórdica y comparable al de otras zonas mediterráneas. Pero estando rodeada

* Versión española del «report» publicado por el Instituto Internacional de Castillos Históricos, IBI, en su Boletín.

Planos de F. Bordeje. Dibujos de F. Castillo. 
por mar y altas montañas, los habitantes de la Península no podían desplazarse a nuevas tierras cada vez que se producía una invasión, lo que imponía una fuerte resistencia inicial y una asimilación completa más tarde. De esta manera se desarrolló un conjunto de pobla-

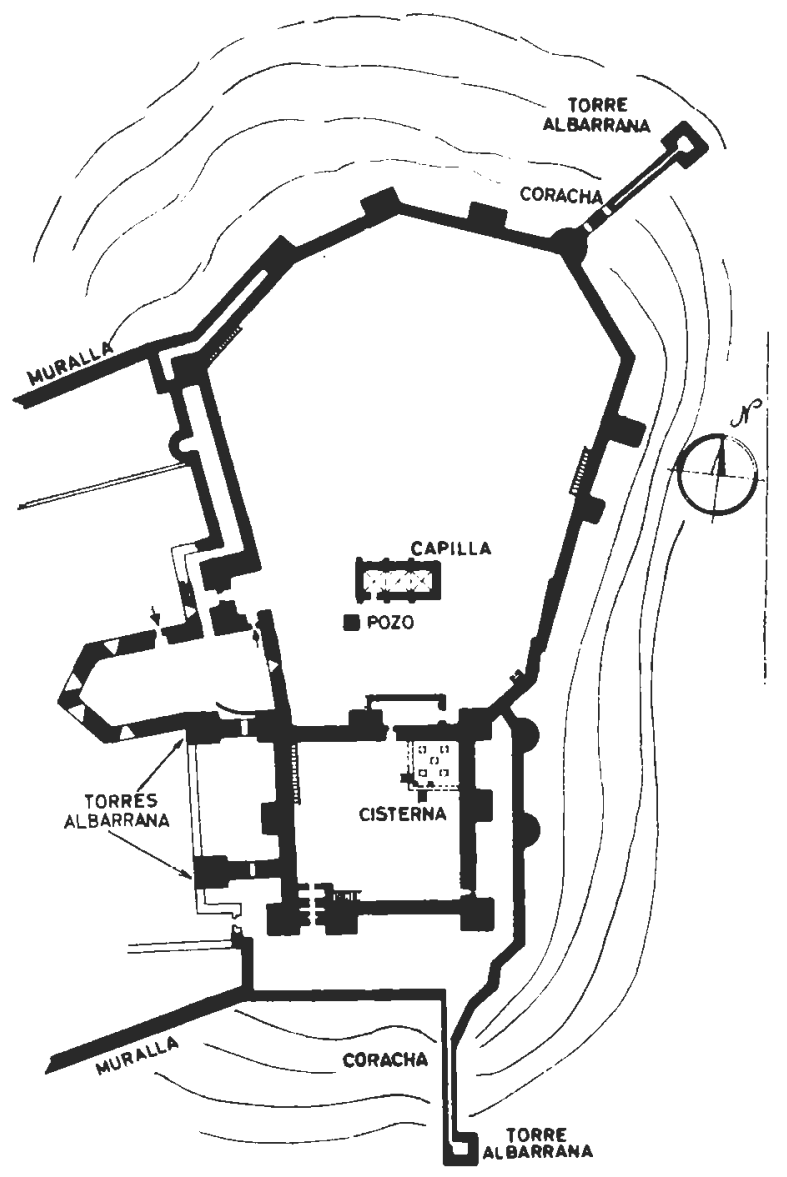

FIg. 1. Castillo de Trujillo, lípico ejemplar árabe del siglo XI que ba conservado su plania original, aun cuando cnire los siglos XIII v $X V$ se le añadiera la capilla y olros ele$0 \quad 510152025 \mathrm{~m}$ mentos.

ciones autóctonas con un gran sentido de la libertad y de la individualidad. Es lógico que si estos grupos estaban siempre dispuestos a resistir otras influencias, habían de preocuparse de erigir puntos fortificados contra vecinos y extraños.

88 
Tras las influencias púnica y helénica, enraizadas en la base del carácter y personalidad hispanos, se establecen en la Península los cartagineses y los romanos, aunque solamente éstos son capaces, tras una lucha larga y cruenta, de establecer su dominio sobre toda la Peninsula, con ia excepción de las zonas montañosas del Norte que queda-

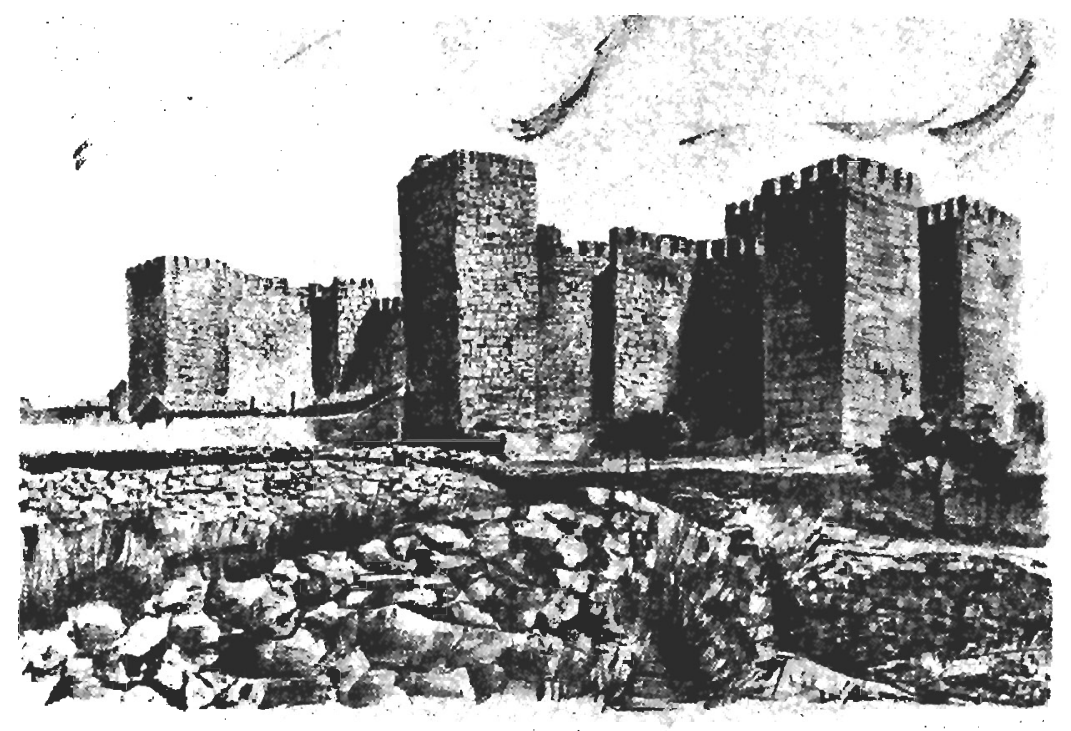

Fig. 2. Castillo de Trujillo.

rian aun aisladas por un "limes». Así se desarrolla una civilización hispano-romana, llena de peculiaridades, que no se encuentran en el resto del Imperio, ya que España, la hija mayor del Lacio, es, tras de Italia, el país más romanizado de Occidente. Esa intensa romanización fue otro de los fundamentos del carácter español, de nuestro idioma, el más afín, con el italiano, a la lengua latina, y de nuestras fortificaciones, basadas en la red romana de puntos dominantes, de campamentos y de cercas de ciudades.

El desmoronamiento del Imperio romano vuelve a sumir a Europa en la oscuridad cultural, pero la cultura clásica sigue brillando al Este, en Bizancio, y al Oeste, en España e Irlanda. Tras las correrías de los suevos, vándalos y alanos y el dominio por Bizancio de una parte de 
Andalucía, los visigodos, uno de los pueblos más civilizados de entre todos los bárbaros, por haber tomado contacto ya en el Danubio con la civilización bizantina, consiguen imponerse como clase gobernante en España y sur de Francia. La Bética, patria del emperador Trajano y del filósofo Séneca, con su gran genio civilizador y su poderosa facultad de asimilación, atrae a los visigodos, que desarrollan alli una floreciente civilización, de la cual San Isidoro de Sevilla, el primer enciclopedista europeo, es uno de sus grandes exponentes. Pero las contiendas civiles resquebrajan su fortaleza y hacen que el dominio sobre los nueve

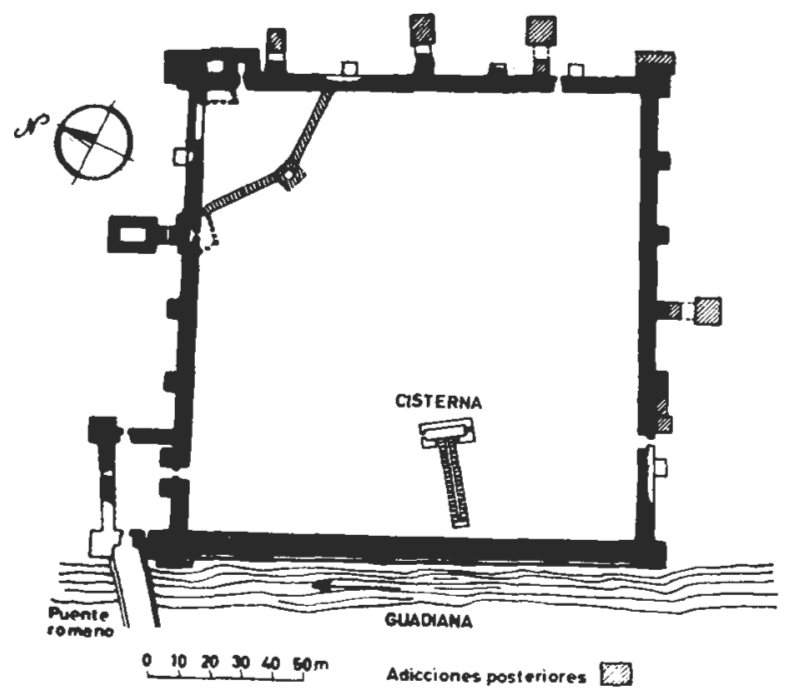

F1G. 3. Alcuzaba de Mérida, construido por los árabes en el siglo XII sobre fundamentos romanos, bello ejemplar de ciudadela tipo bizantino. Posteriormente sirvió como conventual de la Orden de Santiago.

millones de hispanos cambie nuevamente de manos, apartando a España del camino de Europa y rompiendo su unidad política.

Unos cuantos miles de musulmanes de diversas procedencias toman fácilmente el control de la Península, con la excepción de las zonas cantábricas y pirenaicas, y establecen un dominio que durará casi ocho siglos, aun cuando sus divergencias internas favorecen la creación de muchos núcleos autónomos o disidentes cuya extensión y autoridad varian fácilmente. Los árabes traen de nuevo la civilización oriental, llegando a hacer de Iberia el país más orientalizado de Europa, a pesar de estar en su extremo oeste. Muy pragmáticos, no aportan nada suyo, al menos en un principio, y utilizan todos los elementos culturales que aqui encuentran. Cuando el Islam se divide y el califato occidental se establece en Córdoba, afluyen a esta capital sabios árabes, judíos, etc., 


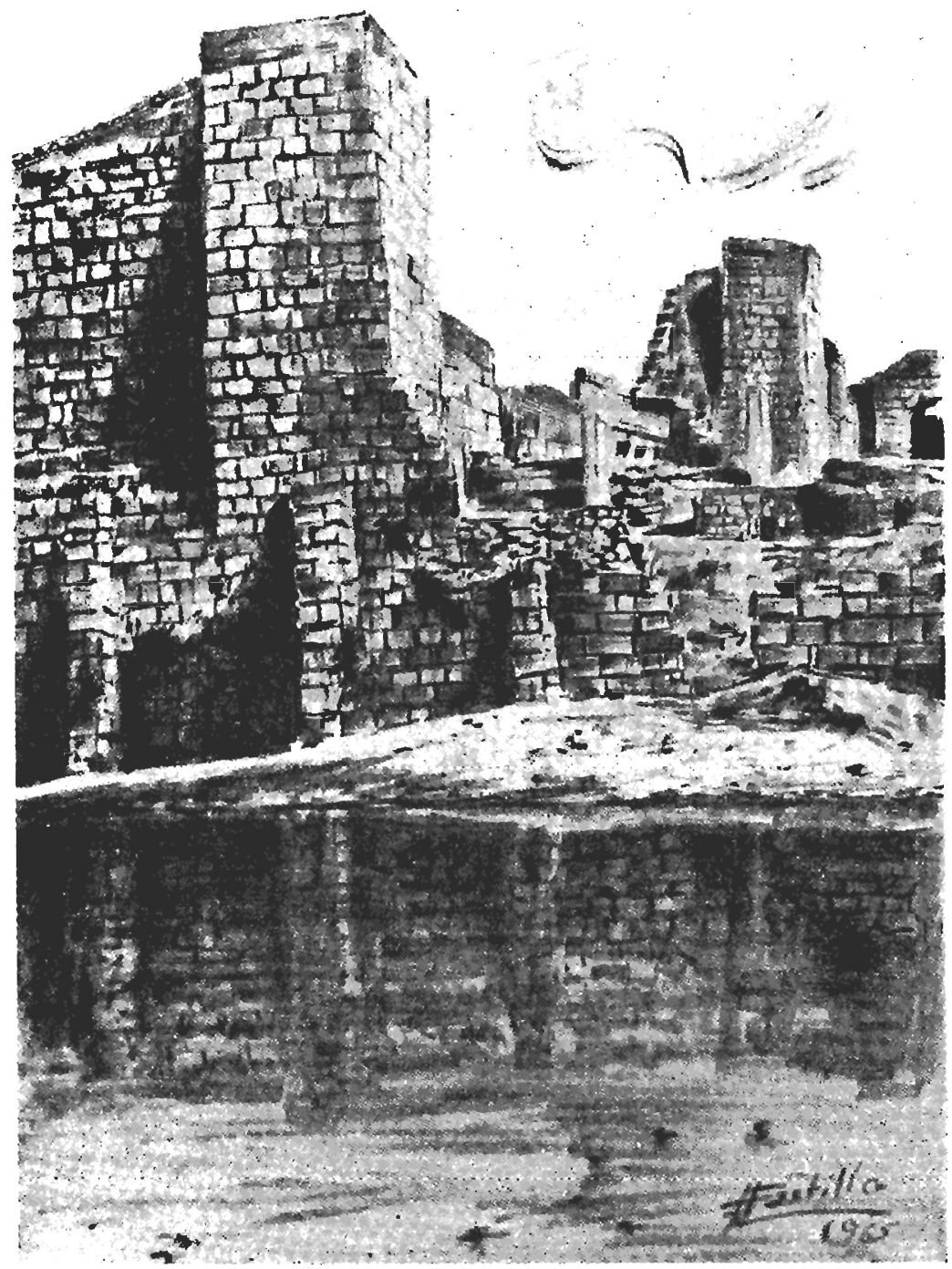

Fig. 4. Alcazaba de Mérida. 
convirtiéndola en la antorcha intelectual de la época, con la más importante universidad de todo el mundo (en la cual se ofrecian al estudioso hasta cuatrocientos mil volúmenes), y, al decir de la época, con sus famosos palacios, trescientas mezquitas, cincuenta hospitales, setenta bibliotecas, etc. Esta aportación cultural fue prontamente absorbida y amalgamada con los conocimientos anteriores, dando como resultado la aparición de una civilización hispano-arábiga, muy diferente de la que simultáneamente se desarrollaba en Damasco o en Bagdad, cultura que será irradiada a los reinos cristianos de la Península y al norte africano y entre cuyas manifestaciones está un estilo superior y original de fortificar, que alcanzará su cúspide durante los dominios almorávide y almohade.

\section{Unificación de España e importancia de sus castillos}

La inmediata reacción de los pequeños núcleos cristianos, en las zonas montañosas del Norte, va a necesitar tres siglos para repoblar el Duero y pasar a la ofensiva y otros dos para dejar reducido al poder árabe el reino de Granada, que sólo se liberará doscientos cincuenta años después. Por ello los hispanos han de concentrar todo su esfuerzo en esta gran cruzada que da un tremendo ímpetu a la construcción de fortificaciones. España no puede participar directamente en la vida europea, pero, según Menéndez Pidal, la reconquista es la más valiosa colaboración que ningún pueblo ha aportado a la gran disputa del mundo entablada entre el cristianismo y el Islam. Además, aquí se desarrollan los estilos mozárabes y asturiano, precursores del románico, aquí se fundan las primeras libertades municipales (que evitan por mucho tiempo el establecimiento del feudalismo) y aquí se recupera para toda Europa el conocimiento clásico, perdido en su versión original, que las escuelas españolas de traductores ( $y$ especialmente la que en Toledo animaran el arzobispo Raimundo y Alfonso $\mathrm{X}$, el Sabio) van a verter al latín, al hebreo o a las lenguas vernaculares, difundiendo por todo el Occidente las olvidadas fuentes de la cultura clásica.

Solamente cuando el califato de Córdoba se ha descompuesto en los reinos de taifas, los cristianos empujan sus fronteras desde el Duero hasta el Tajo, comenzando a tener real importancia sus reinos y, por ende, sus castillos, que han de servir a los aguerridos y modestos núcleos de guerreros cristianos enfrentados a la organización unitaria de las ciudades árabes. El condado de Castilla se ha desarrollado en un reino absorbente, con una política intrépida y democrática, que al cesar el empeño imperial leonés, actuará como fermento de la unidad 
española alcanzada por los Reyes Católicos, dando fin al estado permanente de guerra y a la subsiguiente necesidad nacional de fortificar.

Ya antes de esta unión, y no teniendo suficiente campo en la Península, Aragón había intervenido en Nápoles, Sicilia y Grecia. El descubrimiento de América y de las Islas Filipinas, y el hecho de estar unidos a la corona española los Países Bajos, el Rosellón, el Franco Condado, buena parte de Italia y una serie de plazas africanas, permitieron que en tiempos de Felipe II se pudiera decir que en sus dominios no se ponía el sol. Esta política volcada hacia el exterior hace que, salvo algunas pequeñas contiendas con Portugal y las guerras de Cataluña y de Sucesión, los españoles luchen siempre fuera de su país, por lo que no se precisa la gran actividad fortificadora anterior.

Cuando, pasando el tiempo, Napoleón ros invade, fuerza una lucha de guerrillas, preludio de las subsiguientes guerras carlistas. Los ejércitos franceses destruyen piezas muy importantes de nuestra arquitectura militar y las unidades carlistas e isabelinas producen, en menor escala, efectos semejantes. Por unas u otras razones, nuestros castillos quedan abandonados, arruinados y considerados como algo inútil y aun peligroso. Se utilizan como canteras, se fuerza su destrucción por motivos de seguridad, se acaba con las murallas por razones urbanísticas, se dedican los restos a indignos usos, tapando huecos, abriendo puertas o ventanas, compartimentando el interior, todo ello ante la pasividad y la incomprensión de quienes, por sus actividades técnicas o artísticas, debían defenderlos públicamente.

Este es el legado que nos hemos encontrado y que el decreto del 22 de abril de 1949 ha tratado de salvar al poner todos los castillos bajo la protección del Estado, haciendo responsables a los alcaldes respectivos de cualquier daño que puedan sufrir.

El énfasis que los españoles pusieron en sus castillos y la extraordinaria importancia que éstos tuvieron en las varias regiones españolas justifica el hecho de que tanto Castilla como Cataluña deriven sus nombres de las palabras castillo y castellano en sus respectivas lenguas vernaculares. Prueba de esta importania nos da el inventario de los castillos españoles, que ya preocupó a Felipe II y que ha sido finalmente realizado por el malogrado arquitecto don Germán Valentín Gamazo en la Dirección General de Bellas Artes. Existen todavía más de 2.500 castillos medievales, de los cuales unos 250 están completos y unos 1.200 tienen el exterior en buen estado. Si al número de castillos añadimos las torres aisladas, los recintos de ciudades, los puentes y molinos fortificados, las iglesias y monasterios acastillados, los alcázares, los "pazos» o palacios fuertes y las fortificaciones abaluartadas se puede estimar en 10.000 el número de obras existentes de arquitectura 
militar. En cuanto a las fortificaciones prerromanas, es muy difícil estimar su número, ya que no se ha podido hacer todavia una labor de prospección sistemática, pero probablemente sean de 10 a 15.000 .

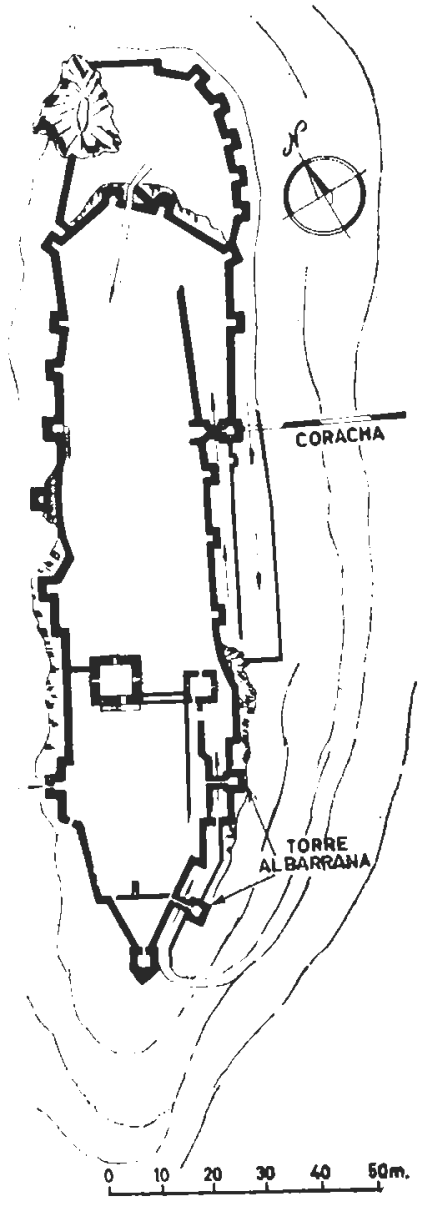

Fig. 5. Castillo de Santa Catalina, en Jaén, levantado por los árabes en el siglo $X I I$ y rebecho en el siglo XIII por muicéares al servicio de Castilla. Ejemplo de casilllo úrabe con torre del homenaje añadida por los cristianos.

Todo ello hace que España sea un país excepcional para el estudio de la fortificación desde los más antiguos tiempos hasta la Edad Moderna y explica el gran valor que a nuestros castillos se da en los distintos círculos internacionales interesados por este tema. 


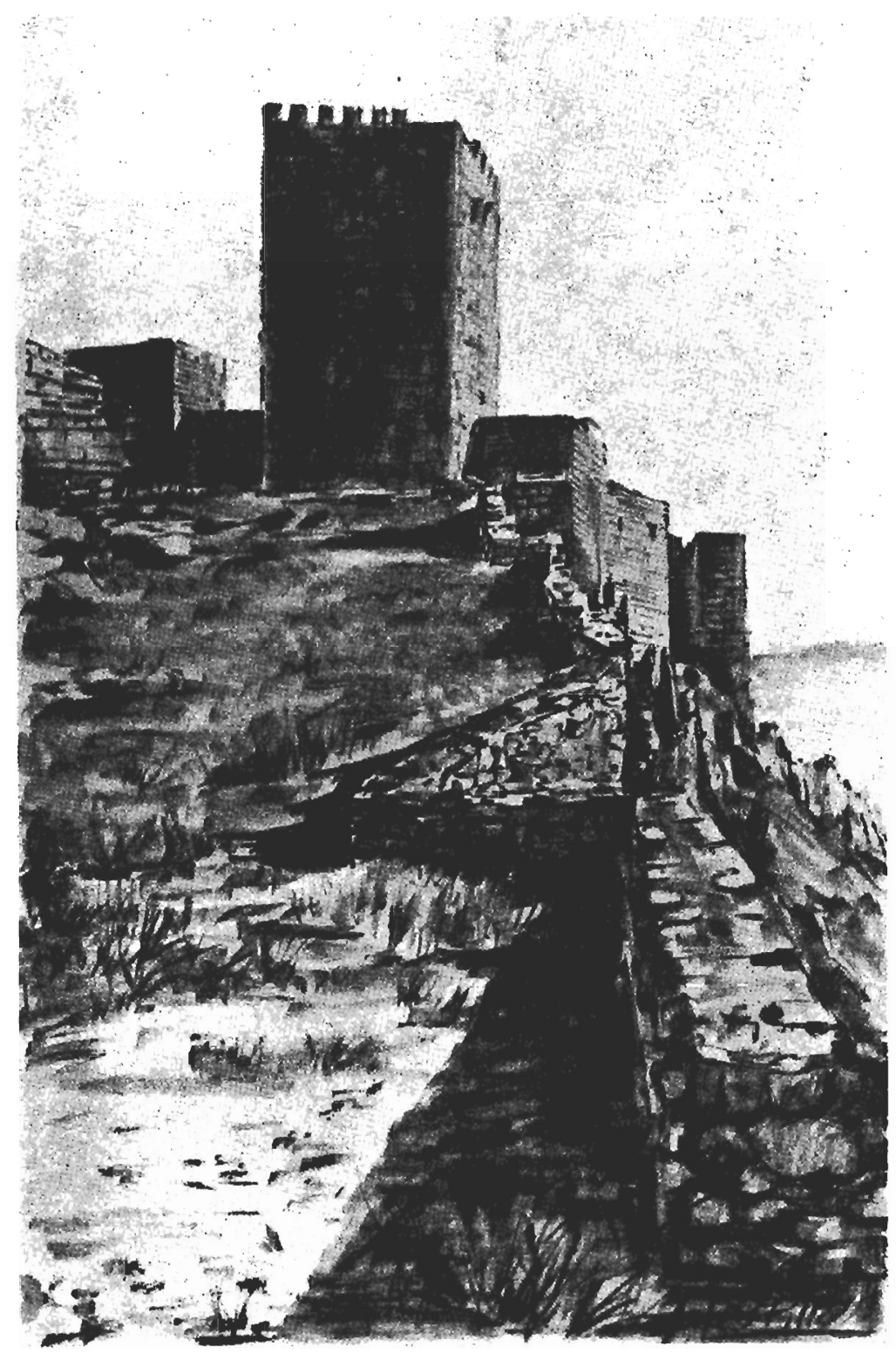

FIG. 6. Castillo de Santa Catalina, en Jaén. 
3. Desarrollo de la arquitectura militar ibérica

Iberia, en los tiempos protohistóricos, estaba cubierta por "castros" y "citanias»-la mayor parte de los cuales no han sido aun suficientemente explorados-que recibieron un impulso especial cuando los fenicios llegaron a España hacia el siglo $\mathrm{x}$ antes de Jesucristo. Son forti-

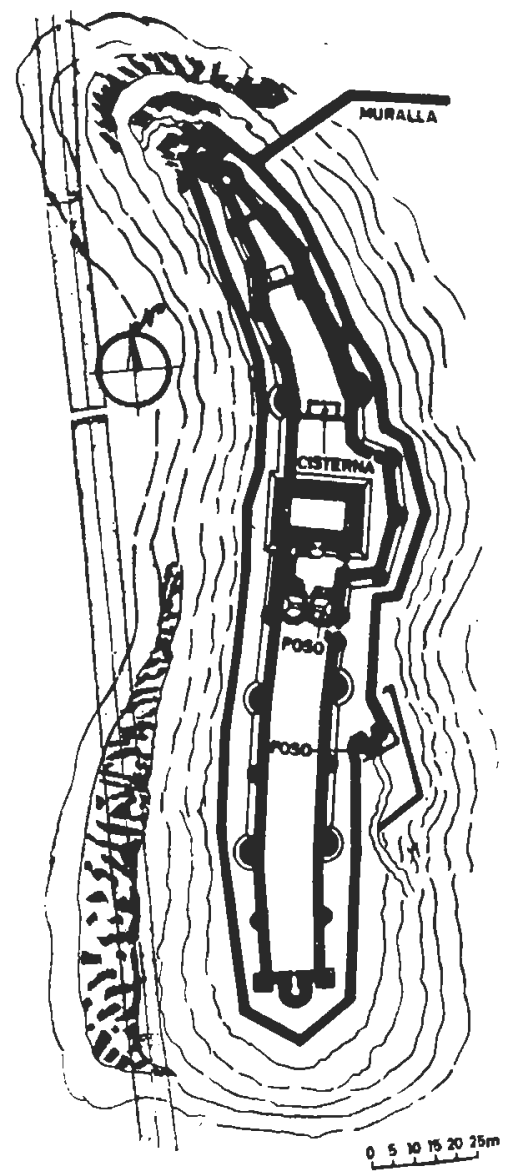

FIG. 7. Castillo de Peñafiel, buen ejem. plo del castillo cristiano del siglo XV. Su forma de barco en una colina alargada y estrecha bace que la fuerte lorre del bomenaje, con numerosas y sucesivas dejensas, resulte aún más imponente.

ficaciones elementales y rudas, aunque ya aparecen los principios eternos de la defensa: adaptación al terreno, propósito de desviar y dominar comunicaciones y accesos, utilización de murallas y fosos a 


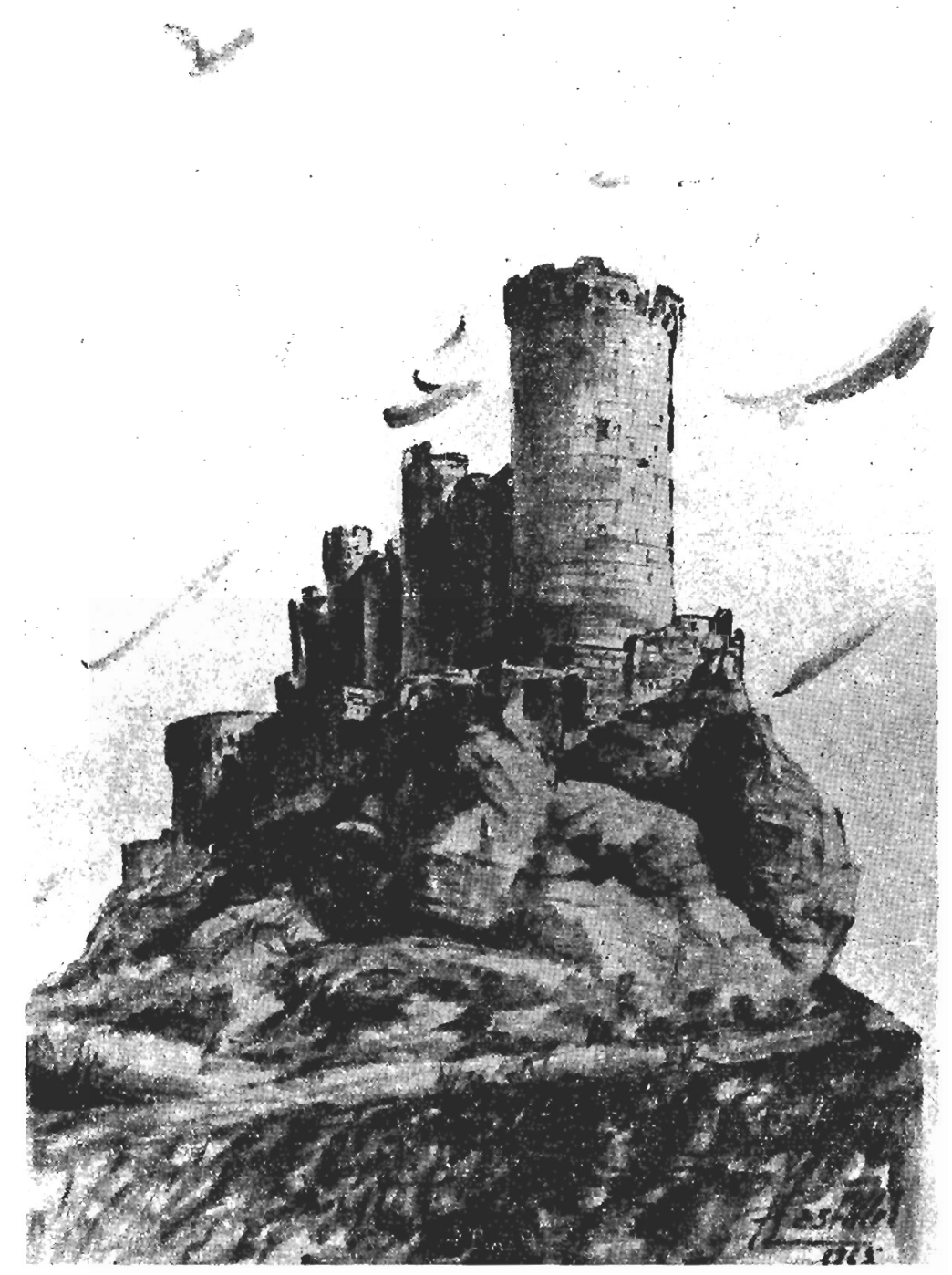

Fig. 8. Castillo de Peñatiel. 
veces múltiples, aplicación del flanqueamiento, etc. Ejemplo de castros ibéricos son Azaila, Millares y Sagunto; de citanias celtas, Coaña, Sobroso, Sanfín y Santa Tecla, y de ciudades celtibéricas, Numancia y Termes. En algunas fortificaciones ibéricas, como las murallas ciclópeas

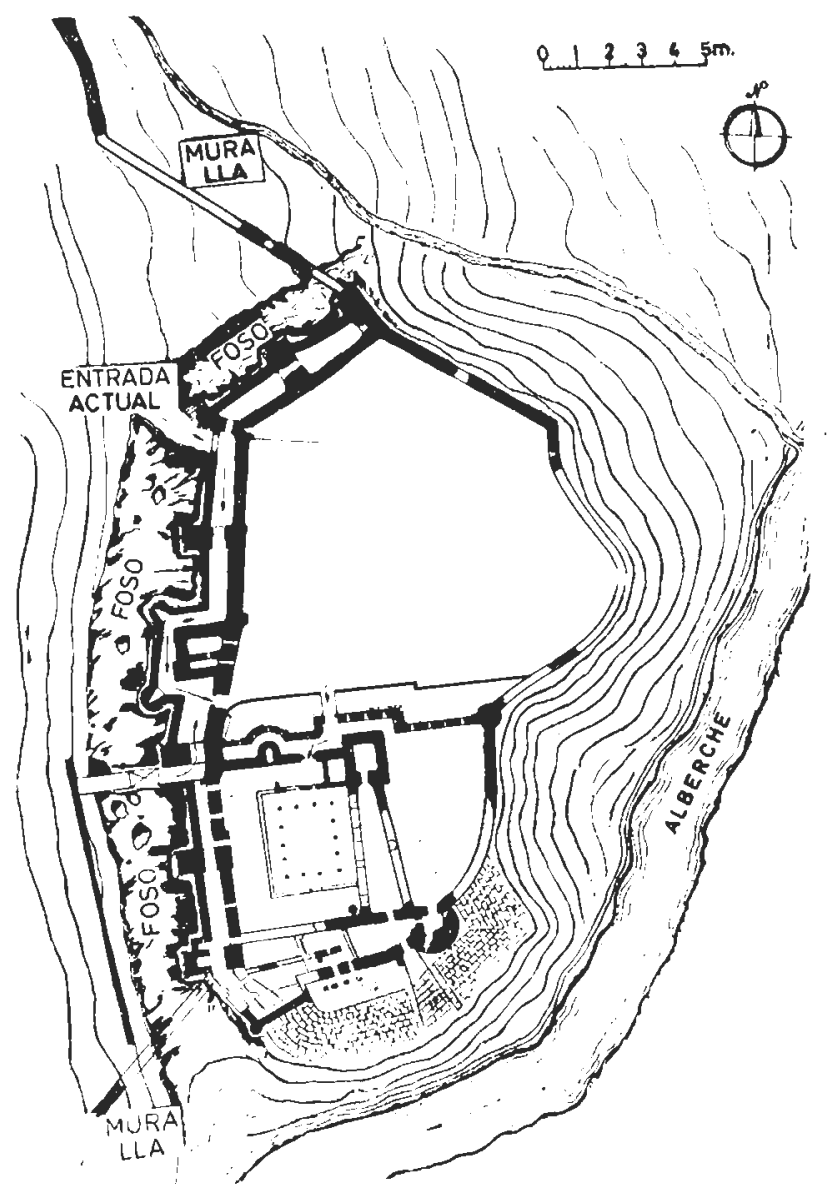

Fig. 9. Castillo-palacio de Escalona, enorme y magnífico ejemplar. de la adaptación simullánea a las necesidades guerreras y cortesanas. Basado en construcciones anteriores, reedificado en el siglo XV $y$ destruido por las tropas de Napoleón, muestra lodavia una superposición de cuerpos de épocas y estilos muy diversos. 


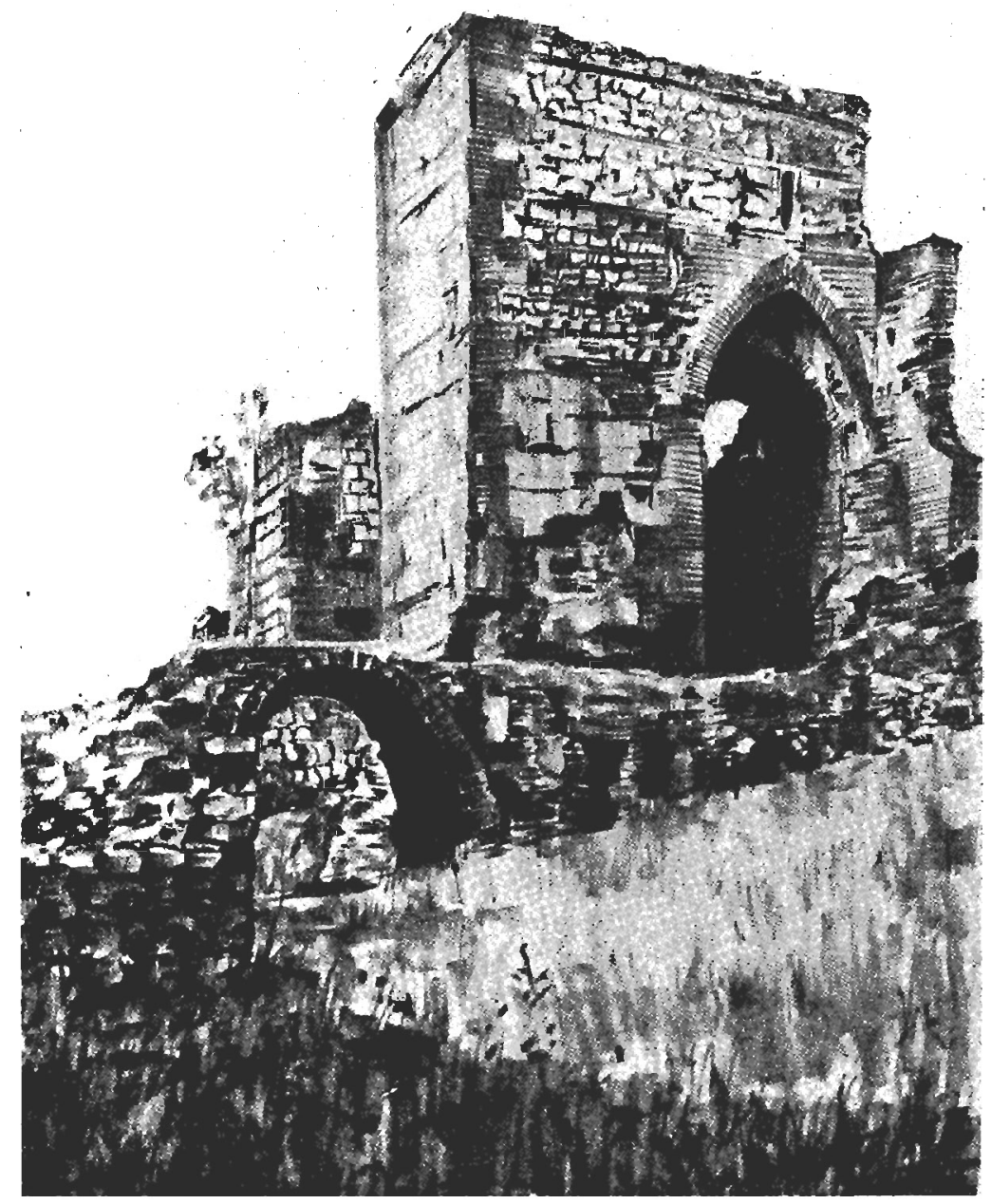

FIg. 10. Castillo-palacio de Escalona. 
de Gerona, Ibros o Tarragona se aprecian claramente influencias púnicas o helénicas. Su fortaleza está evidenciada por el hecho de que todavia están en pie después de tantos siglos y que algunas de ellas resistieron durante mucho tiempo violentos y repetidos asaltos, como los de Anibal contra Sagunto o de varios pretores romanos contra Clunia, Termes y, sobre otdo, Numancia, que sólo fue conquistada por los esfuerzos del gran Escipión el Africano. Adviértase que muchos de estos "castros" o "citanias" fueron después convertidos en fortalezas romanas y más tarde en castillos medievales, ya que una de las características más destacadas de los castillos españoles es la de tener una serie de niveles arqueológicos que suelen remontarse hasta las más lejanas edades.

Durante la dominación romana se levantan en Iberia campos fortificados, fuertes aislados y recintos de ciudades, de los cuales pueden aún verse importantes restos, incorporados en nuestras fortificaciones medievales. Estas defensas van desde Ios «castelli» republicanos (Borja), a través de los "castra estativa» de las legiones (Numancia, Cáceres, Alconétar, Almazán, Mérida), hasta los recintos del bajo imperio (León, Lugo, Astorga, Zaragoza, Barcelona, Gerona). Igual que en el resto de Europa, la seguridad y confianza de la larga pax romana permitió desguarnecer las fortificaciones que luego, igual que hizo Aureliano en Roma, fueron apresuradamente reparadas y rehechas cuando el peligro de una invasión se hizo patente.

La influencia de los visigodos no está aún suficientemente estudiada, especialmente en lo que se refiere a la fortificación. Cuando consiguieron unificar bajo su mandato toda la Península conservaron y ampliaron las murallas anteriores, como en Toledo, Tarragona y Cartagena, y elevaron torres fortificadas, especialmente en los cortijos andaluces. Hasta los tiempos carolingios esta será una actitud común a toda Europa, que se limita a utilizar las defensas que legó el bajo imperio. Esto es también aplicable a los primitivos núcleos cristianos de la Península, cuyas defensas originales son las viejas posiciones romanas y algunas torres aisladas, cuadradas y normalmente sin recinto, que permiten la salvaguardia y vigilancia de las comunicaciones y accesos al norte del Duero.

Los musulmanes introducen en Iberia un sistema de fortificación absolutamente original y superior, que sigue las reglas clásicas y bizantinas adaptándolas a las especiales características de la topografía ibérica. Como Federico Bordeje dice, después de haber dedicado su vida entera al estudio de los castillos, todos los principios de esta escuela de fortificación y poliorcética se han usado tan intensamente en nuestro país que los castillos españoles se pueden estudiar llevando en la mano 
las obras de Eneas, del Anónimo Bizantino o de Filón de Bizancio. Los castillos hispano-árabes en los siglos $\mathrm{Ix} \mathrm{y} x$ no solamente siguen las reglas bizantinas, sino que las desarrollan con énfasis. Según el profesor Terrasse, las torres albarranas, las corochas y las defensas verticales (buheras y buhardas), son felices invenciones de la fortificación española, inexistentes en ninguna otra de aquella época.

Restan todavía en España una larga serie de fortificaciones milenarias, de datación perfectamente conocida, que están intactas o con alteraciones menores, a pesar de los continuos y duros ataques que han sufrido en los tiempos medievales. Los alcazabas de Mérida, Almería, Málaga o Guadix, los castillos de Gormaz, Tarifa, Baños de la Encina, el Vacar, Trujillo, son las fortalezas más completas y antiguas del Occidente, dotadas ya con toda clase de elementos defensivos, cuando en Europa se seguian utilizando las arcaicas motas, con las torres elementales de Foulkes Nerra o de Guillermo el Conquistador. Aún hay que añadir los alcázares suntuosos de Granada, Sevilla, Niebla y Zaragoza y los numerosos recintos de ciudades, entre las cuales mencionamos Avila, Madrigal, Tarifa y Talavera. Este énfasis en la fortificación está justificado por no existir, entre los distintos reinos musulmanes o cristianos, fronteras fijas, sino puntos estratégicos, en zonas despobladas, por entre los cuales penetran las correrías o algarras enemigas que profundizan, a veces, hasta Santiago o hasta Gibraltar. Precisamente, el máximo esplendor de la arquitectura hispano-arábiga tiene lugar en los reinos de taifas, en las épocas almorávide $\mathrm{y}$ almohade, cuando los cristianos van a poder dar un avance decisivo a la reconquista de España, asimilan la cultura de los reinos hispano-árabes y elaboran el auténtico castillo español.

\section{El castillo español}

Cuando los reinos cristianos del Norte hacen sus primeros avances, aparece, a comienzos del siglo XI, el castillo hispano-visigćtico de la línea del Duero, del Alto Aragón, de la Marca Hispánica, rudo, primitivo e inhabitable, donde, como dice Alfonso X, el Sabio, las esposas tenían que dormir junto al señor al lado de los caballos.

Las distintas alianzas y luchas entre los varios reinos musulmanes y cristianos hacen que el esplendor cultural de las taifas pase a los reinos del Norte. El avance hasta el Tajo permite a los cristianos poseer castillos árabes y utilizar trabajadores arabizados que influyen poderosamente en la forma de construir, dando lugar al estilo mudéjar tan 
usado en nuestras fortificaciones y que hace más difícil su datación. Asi, a fines del siglo xI, aparece el auténtico castillo español.

Tanto en los tomados a los árabes como en los de nueva construcción, los cristianos introducen, como símbolo de su soberanía, la torre del homenaje, de tradición nórdica. Se trata de la torre mayor que domina al resto del castillo, y en algunos casos, es la única importante, pero que nunca llega a ser tan grande como el donjon francés y el keep inglés. Situada en el punto culminante o de mejor defensa, está circundada por varios recintos concéntricos (que suelen incluir a la propia

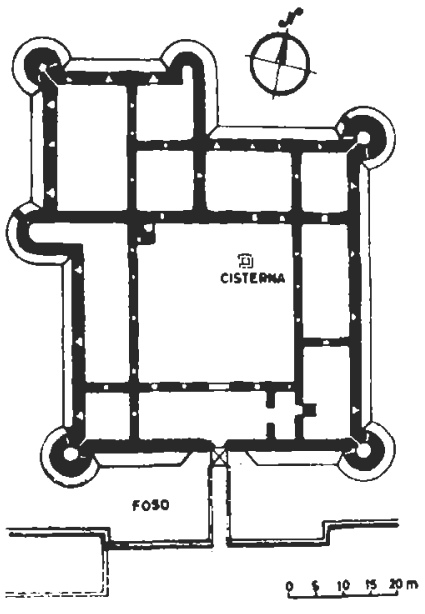

Fic. 11. Castillo-fuerte de Chinchón, bello ejemplar de transición a la fortificación abaluarlada, clevado en el siglo XVI bajo influencias italiamas y destruido por las tropas de Napoleón.

torre del homenaje) formados por fuertes murallas protegidas por numerosas torres cuadradas flanqueantes. Un foso, generalmente seco, existe en los lados sin defensa natural. La entrada a la torre se abre en el segundo piso y está protegida por una serie de defensas sucesivas, entre ellas la buharda o balcón amatacanado. Próximo se encuentra el algibe o cisterna, en muchos casos todavía en uso.

He aquí otras características del castillo español (sea hispano-árabe o hispano-cristiano) de los siglos xry al Xv, parte de las cuales fueron incorporadas a la fortificación abaluartada a partir del siglo xvr.

Antemurales o barreras, reminiscencia de la fortificación romana.

Puertas desenfiladas, en doble codo, con sucesivas defensas, a veces situadas lateralmente, muy elaboradas y protegidas por dos torres flanqueantes o abiertas en una potente torre.

Torres pentagonales, especialmente en los lugares peligrosos o vulnerables. 
Torres albarranas, destacadas de los recintos y unidas a ellos por un puente, o separadas en posiciones estratégicas.

Corachas, que dividen en sectores las zonas de asedio e impiden el paso de la contravalación exterior.

Cremalleras, que evitan o economizan los órganos del flanqueamiento.

Buhardas para la defensa vertical exterior del castillo y buheras para la defensa vertical de las puertas.

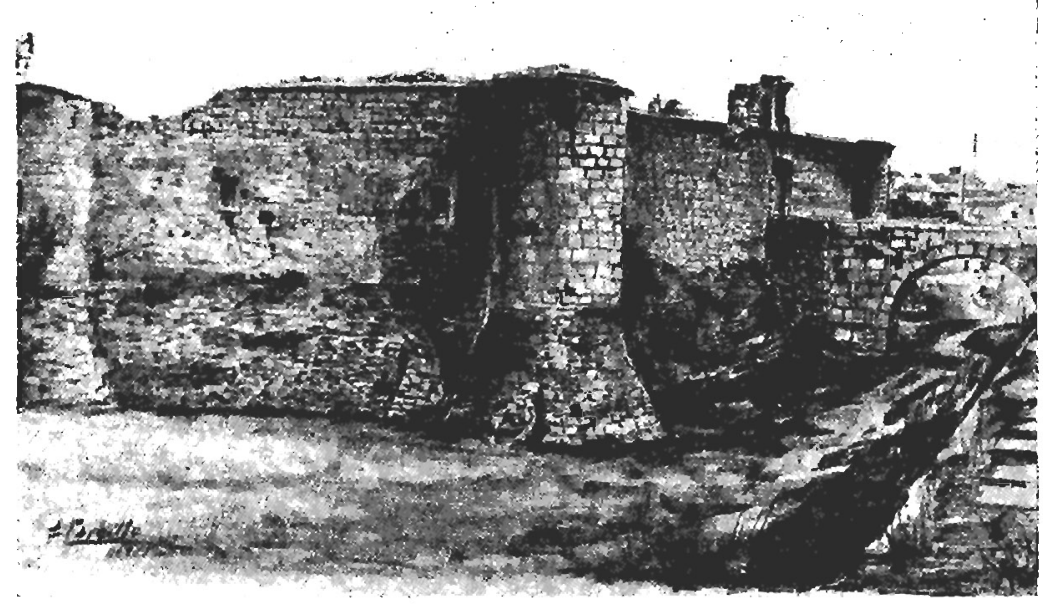

Fic. 12. Castillo-fuerle de Chinchón.

A estos elementos ha de añadirse otra circunstancia esencial en los castillos españoles y es que su erección, en terrenos reconquistados y poco poblados, no respondía a razones aisladas ni a caprichos señoriales, sino a necesidades verdaderamente estratégicas. Así formaban grandes líneas expresamente coordinadas por los diversos accidentes políticos o topográficos, para una mejor defensa de la frontera de los reinos y de las líneas de comunicación o para servir de lugares de refugio tras cada jornada de camino. Ello significa que los castillos españoles hasta el siglo xiv son simples castillos de guarnición, normalmente erigidos en ásperas e inaccesibles posiciones impuestas por el 
terreno $\mathrm{y}$, por tanto, sin condiciones de habitabilidad para la vida moderna. Su sobria y robusta silueta es característica del paisaje español, donde los hundimientos geológicos produjeron tantas eminencias y pequeñas mesetas, rodeadas de escarpadas laderas, asiento ideal de castillos.

La influencia oriental que la Iberia romana recibió de visigodos, bizantinos y árabes sigue presente hasta el fin de la Edad Media. En el siglo xII los castillos españoles reciben una nueva influencia bizantina a través de las órdenes de los templarios y hospitalarios, que vienen a tomar parte en la reconquista y que elevan aqui sus castillos-conventos como Loarre, Zorita o Turégano, en muchos casos copias de los castillos francos en Palestina.

A partir del siglo xIII, cuando la gran batalla de las Navas abate para siempre la hegemonía musulmana en la Península, comienzan las pretensiones nobiliarias de los señores cristianos, hasta entonces sujetos y dominados por el poder real, apoyado en los Consejos municipales. Surgen entonces algunos auténticos señorios, que no serán nunca tan feudales como en Inglaterra o Francia, y que siguen sometidos a la autoridad real. Se puede afirmar que sólo a partir del sjiglo xv las casas nobles de España, incluso las más importantes, poseen castillos propios, y comienzan a usar los títulos de duque y marqués, que se añaden al clásico de conde. Hay que exceptuar Cataluña, debido a viejas tradiciones de los tiempos de la marca hispánica, Aragón y Valencia, donde, en un régimen señorial, se crearon muchas baronías en el momento de su reconquista, y Galicia, por el alejamiento del poder real. En estas regiones existian con anterioridad limitadas manifestaciones de dominio feudal.

Pero en el resto de España la aparición de los castillos específicamente señoriales sucede cuando ya la artillería va a hacer inútiles los elementos clásicos de fortificación. En efecto, las armas de fuego son utilizadas, con toda seguridad, por los árabes en 1331 contra Orihuela y Alicante y por los cristianos en 1342 contra Algeciras. Aunque tarda cierto tiempo en imponerse, cuando lo hace revoluciona la fortificación medieval, forzando la transformación o el abandono de los viejos castillos y obligando a que las nuevas construcciones sean totalmente distintas o puramente decorativas. Otro elemento que contribuye también a la reforma del castillo español son los contactos con el extranjero a través de las peregrinaciones a Santiago de Compostela y de la unión con importantes territorios de Italia. Todo ello hace que la mayor parte de los elementos añadidos a los castillos señoriales sean puramente decorativos, persiguiendo sólo impresionar a los extraños y alcanzar bellas líneas artísticas. Asi los castillos de la mitad del siglo xv se ca- 
racterizan por sus altivas y esbeltas torres del homenaje, sus guaitas y torrecillas, sus cintas de matacanes (muchas veces falsos) y el cúmulo de elementos decorativos que aumentan su imponente y majestuosa grandeza. Sin embargo, algunas de estas construcciones señoriales como Coca, Guadamur, Peñafiel, Valencia de Don Juan o Portillo son todavía recias fortalezas de guerra. Otros, como Escalona, juntan al castillo el palacio y al albacar el campo de torneos.

El influjo de la artillería, a que nos hemos referido anteriormente, se deja sentir plenamente en el siglo xvi en aquellos castillos usados como lugares fuertes. De la época inicial o de transición, España posee bellos ejemplares como Grajal, Berlanga de Duero, las Navas del Marqués, Chinchón, etc., en algunos de los que se advierten influencias italianas, con la introducción de grandes torrioni (precursores del baluarte) que se desenvuelven con sus enormes masas y sus especiales disposiciones para emplear y resistir la artillería. Más adelante es preciso añadir troneras, taludes, galerías y otros elementos. Hay que rebajar la línea magistral, ganando en anchura lo que se pierde en altura, agrandar los fosos y cortar el ataque por una serie de obras exteriores que eviten los asaltos por sorpresa y alejen al enemigo. Pero lo más característico es que las torres pentagonales ya utilizadas en España para mejorar la defensa de los flancos, se desarrollan claramente en baluartes de forma poligonal y que una figura geométrica, polígono o estrella, es la base del diseño general de la fortaleza, que aunque se sigue llamando castillo, ha dejado de serlo.

Durante esta época, que coincide con la hegemonía española, nuestra arquitectura militar dejó importantes ejemplos, no sólo en la Península, con Jaca, San Sebastián, Pamplona, Barcelona o Badajoz, sino en otras zonas como en Nápoles, con Castelnovo o San Telmo; en Rosellón, con Salses; en el norte de Africa, con Ceuta y Melilla, y en América, a lo largo de las costas del Pacífico y del Atlántico, cuyo rosario de fuertes es el punto culminante y fulgurante de nuestra arquitectura militar. Ingenieros españoles como Pedro Luis Scriba o Luis Pizaño cuentan entre los primeros en escribir sobre las modernas técnicas de fortificación y de artillería, y juntamente con Firrufino, Fernández de Medrano, Zepeda, etc., pueden considerarse como los precursores de los grandes maestros como Coehorn y Vauban.

En general, el castillo español, con su infinita variedad y riqueza en plantas y elementos defensivos, mantiene su carácter militar y las razones eminentemente estratégicas de su construcción. Por ello, salvo əlgunas excepciones, carece de fin utilitario personal o señorial, por lo que los nobles han de construir sus residencias en las villas y ciudades. Así abandonan campiña y castillos a su suerte, que se vuelve aún más 
negra cuando el renacimiento empobrece a las casas nobiliarias. Todo ello, y el deseo de los sucesivos reyes, cada vez más absolutos, de acabar con el naciente feudalismo, destruyendo algunas de sus fortificaciones y paralizando la construcción de otras, hace que los castillos españoles sean abandonados en su gran parte. La corona, propietaria de cientos de castillos, sólo conserva los más importantes en costas y fronteras, transformándolos en ciudadelas abaluartadas. Las familias nobles, algunas con casi el centenar de castillos (Alba, Infantado, Medinaceli), sólo mantienen como residencias algunos de ellos.

Andando el tiempo, aparece otra amenaza, ahora psicológica. Las ideas liberales y antiseñoriales del siglo xix señalan a los castillos como simbolo de la tiranía y del feudalismo (que realmente no llego a tener fuerza en nuestro país) e incitan a su desprecio, abandono, saqueo y destrucción.

Pero los que han llegado a nuestros días tienen aún su planta y características originales, teniendo, por ello, un extraordinario interés desde el punto de vista de la evolución de la arquitectura militar. Su original personalidad los distingue de los similares extranjeros, superiores por sus parques, por el lujo de su construcción y por sus condiciones residenciales, pero que, en conjunto, son posteriores o incompletos en lo esencial de toda fortaleza, es decir, en el uso de los principios fundamentales de poliorcética y fortificación para los que fue expresamente construida. 